\title{
Geoprocessamento no Trato de Controle de Características Urbanas
}

\author{
Control of Urbans Caracteristics Dealt by Geoprocessing \\ Filipe Lima de Almeida ${ }^{1}$ \\ Giovani Miranda Costa ${ }^{1}$ \\ Ricardo Passos Nascimento ${ }^{1}$ \\ Vanessa Moreira Leite ${ }^{1}$ \\ Professor Pós-Doutor Diomar César Lobão ${ }^{2}$ \\ Professor Pós-Doutor Marcelo Genestra ${ }^{2}$ \\ Professor Doutor Tito Lívio Gomes Osório ${ }^{2}$ \\ Professor Mestre Flavio Campos Carelli ${ }^{2}$
}

\footnotetext{
${ }^{1}$ Discentes do Curso de Graduação Sistemas de Informação / UniFOA

${ }^{2}$ Docentes do Curso de Sistemas de Informação do UniFOA
}

Contato: Diomar Cesar Lobão

Email: dclobao@yahoo.ca

Centro Universitário de Volta Redonda / UniFOA

Av Paulo Erley Alves Abrantes,1325 - Três Poços

CEP - 27264-350

Volta Redonda / RJ

\section{Resumo}

O geoprocessamento é um conjunto de tecnologias que coleta, armazena, processa e disponibiliza informações geográficas sendo compostas por soluções em hardware, software e peopleware. Essas informações são adquiridas e demonstradas com o uso de planilhas e relatórios no papel. Trata-se da fusão da geomática com a computação, especificamente a área de Sistema de Informação. Atingindo áreas bastante heterogêneas, esta tecnologia é bastante utilizada em áreas de gestão municipal, meio ambiente, planejamento estratégico de negócios e agronomia, tornando-a bastante utilizada em vários países como parte de organizações governamentais e não governamentais. Colaborando com essas entidades, auxilia o controle de cadastro técnicos urbanos, rurais e florestais, gerenciamento de saúde publica, previsão de safras, planejamento e uso do solo, gestão de bacias hidrográficas, tratamento de curvas de nível para plantio, detecção de pragas, gerenciamento de energia elétrica e telecomunicações. O presente trabalho trata-se especificamente da 
discussão do controle de características urbanas utilizadas pelo geoprocessamento. Um exemplo de aplicação na especificação de um sistema dedicado ao controle de IPTU é tratado em detalhes neste trabalho.

Palavras - Chave: Geoprocessamento, Urbanismo, SIG - Sistema de Informação Geográfica

\begin{abstract}
Geoprocessing is a set of technologies that collects, stores and processes geographic information becoming it available, being composed for solutions in hardware, software and peopleware. These information are acquired and shown with the use of spread sheets and reports. This is about the fusion of the geomática with the computation, specifically at the area of System of Information. Reaching areas greatly heterogeneous, this technology is used in: municipal management; environment; business strategic planning and at the agronomy, being used in some countries by the governmental and not governmental organizations. In those entities, it assists at the technical control of urban, rural and forest cadastre, at the public health management, at the harvests forecast, at the planning and ground use, at the management of hydrographical basins, at the treatment of level curves for planting, at the plagues detection, at the management of electrical energy and the telecommunications. The present work is specifically about the characteristics of the urban control by the use of the geoprocessing. In this work is treated in details an example of this application in the specification of a dedicated system to the IPTU control.
\end{abstract}

Key-words: Geoprocessing, Urbanism, GIS (Geographic Information System)

\title{
1. INTRODUÇÃO
}

Desde os primórdios, o homem utiliza mapas para sua orientação. E conforme o tempo passou e tudo foi se aprimorando, esses mapas também foram trazendo mais detalhes territoriais e sendo confeccionados para vários fins, captando diversos tipos de informações geográficas, econômicas e culturais.

Atualmente, existe o controle de fatores que são deveras complexos para se representar em papel. Para isso, surgiu o Geoprocessamento, que é o processamento informatizado de dados georeferenciados. Ou seja, o geoprocessamento é um conjunto de tecnologias que coletam, tratam e processam dados e disponibilizam informações com referência geográfica, sendo assim uma grande ferramenta para tomada de decisão. Para isso, existem sistemas específicos para o uso integrado das informações espaciais, chamados GIS ou SIG - Sistemas de Informação Geográfica. Para a coleta desses dados, 
existem outros, como o Sistema de Posicionamento Global (exemplo, GPS), Sensoriamento Remoto por Satélites, Cartografia Digital, Aerofotogrametria, Geodésia e Topografia Clássica, dentre outros.

O Geoprocessamento é utilizado para diversos fins, como Cartografia, Mapeamento, Análise de Recursos Naturais, Comunicações, Energia, Planejamento Urbano e Regional. No Brasil, existem muitos projetos pioneiros relacionados ao geoprocessamento, como na Amazônia e em cidades históricas. Uma das principais aplicações do geoprocessamento é na gestão municipal, onde grande parte do trabalho depende da localização. Cadastro imobiliário, saúde pública, tratamento de água e esgoto, luz, gás, transporte são alguns dos diversos fatores que o geoprocessamento trata em um município.

\section{GEOPROCESSAMENTO}

A coleta de informações sobre a distribuição geográfica de recursos minerais, propriedades, animais e plantas é uma parte importante das atividades das sociedades organizadas. Até recentemente, no entanto, isto era feito apenas em documentos e mapas em papel; isto impedia uma análise que combinasse diversos mapas e dados. Com o desenvolvimento simultâneo, na segunda metade deste século, da tecnologia de Informática, tornou-se possível armazenar e representar tais informações em ambiente computacional, abrindo espaço para o aparecimento do Geoprocessamento. Nesse contexto, o termo Geoprocessamento denota a disciplina do conhecimento que utiliza técnicas matemáticas e computacionais para o tratamento da informação geográfica e que está influenciando as áreas de Cartografia, Análise de Recursos Naturais, Transportes, Comunicações, Energia e Planejamento Urbano e Regional (Pontes, 2002).

Segundo Camara, Souza e Freitas (1996), geoprocessamento é o conjunto de tecnologias voltadas à coleta e tratamento de informações espaciais para um objetivo específico. Geoprocessamento é destinado ao processamento de dados referenciados geograficamente desde a sua coleta até a geração de saídas na forma de mapas convencionais, relatórios, arquivos digitais, etc; devendo prever recursos para sua estocagem, gerenciamento, manipulação e análise.

O termo Geoprocessamento tem sido confundido com o termo Geomática e tomado como sinônimo de SIG (Sistema de Informação Geográfica). Geoprocessamento resulta da fusão da Geomática com a Ciência da Computação, especificamente a área de Sistemas de Informação. Nesta visão os Sistemas de Informação Geográfica (SIG/GIS) são tecnologias de Geoprocessamento que lidam com informação geográfica na forma de dados geográficos.

Por sua vez, dados geográficos podem ser classificados como dados espaciais e dados de atributos. A Geomática reúne metodologias e tecnologias das Ciências Geodésicas com o formalismo matemático, com o objetivo de coletar, tratar e processar dados espaciais, tornando-os aptos a serem utilizados por tecnologias SIG. Estes dados permitem que se 
conheça a estrutura geométrica de entes espaciais (casa, rua, rio, parcela de solo, viatura, etc.) bem como sua posição no espaço geográfico (Rafaeli Neto, 2005).

Segundo Laskowski e Ribeiro (2005), o geoprocessamento é o conjunto de pelo menos quatro categorias de técnicas relacionadas ao tratamento da informação espacial:

- Técnicas para coleta de informação espacial (Cartografia, Sensoriamento Remoto, GPS, Topografia Convencional, Fotogrametria, Levantamento de dados alfanuméricos);

- Técnicas de armazenamento de informação espacial (Bancos de Dados - Orientado a Objetos, Relacional, Hierárquico, etc.);

- Técnicas para tratamento e análise de informação espacial, como Modelagem de Dados, Geoestatística, Aritmética Lógica, Funções topológicas, Redes;

- Técnicas para o uso integrado de informação espacial, como os sistemas GIS Geographic Information Systems, LIS - Land Information Systems, AM/FM - Automated Mapping/Facilities Management, CADD - Computer-Aided Drafting and Design.

Segundo Gewin (2004), as geotecnologias estão entre os três mercados emergentes mais importantes da atualidade, junto com a nanotecnologia e a biotecnologia.

\subsection{Dados}

Segundo Pontes (2002), existem 4 tipos de dados em Geoprocessamento:

- Dados Temáticos: descrevem a distribuição espacial de uma grandeza geográfica, expressa de forma qualitativa, como a aptidão agrícola de uma região. Estes dados, obtidos a partir de levantamento de campo, são inseridos no sistema por digitalização ou, de forma mais automatizada, a partir de classificação de imagens.

- Dados Cadastrais: cada um de seus elementos é um objeto geográfico, que possui atributos e pode estar associado a várias representações gráficas. Por exemplo, os lotes de uma cidade são elementos do espaço geográfico que possuem atributos (dono, localização, valor venal, IPTU devido, etc.) e que podem ter representações gráficas diferentes em mapas de escalas distintas. Os atributos estão armazenados num sistema gerenciador de banco de dados.

- Redes: em Geoprocessamento, o conceito de "rede” denota as informações associadas a: Serviços de utilidade pública, como água, luz e telefone; Redes de drenagem (bacias hidrográficas); Rodovias. No caso de redes, cada objeto geográfico (ex: cabo telefônico, transformador de rede elétrica, cano de água) possui uma localização geográfica exata e está sempre associado a atributos descritivos presentes no banco de dados. As informações gráficas de redes são armazenadas em coordenadas vetoriais, com topologia arco-nó: os atributos de arcos incluem o sentido de fluxo e os atributos dos nós sua impedância (custo de percorrimento).A topologia de redes constitui um grafo, que armazena informações sobre recursos que fluem entre localizações geográficas distintas.

- Imagens: obtidas por satélites, fotografias aéreas ou scanners aerotransportados, representam formas de captura indireta de informação espacial. Armazenadas como 
matrizes, cada elemento de imagem (denominado pixel) tem um valor proporcional à energia eletromagnética refletida ou emitida pela área da superfície terrestre correspondente.

\subsection{Geoprocessamento no Brasil}

Num país de dimensão continental como o Brasil, com uma grande carência de informações adequadas para a tomada de decisões sobre os problemas urbanos, rurais e ambientais, o Geoprocessamento apresenta um enorme potencial, principalmente se baseado em tecnologias de custo relativamente baixo,em que o conhecimento seja adquirido localmente (Pontes,2002).

Segundo Rafaeli Neto (2005), o Brasil é um grande consumidor de tecnologias SIG. Eventos das séries GisBrasil e GeoBrasil, fundamentalmente destinados aos usuários de SIG, têm contribuído sensivelmente para a popularização dessas tecnologias. Empresas têm investido pesadamente no desenvolvimento destes sistemas para atender um mercado que cresce vertiginosamente. Muitos profissionais têm buscado informações sobre o assunto.

\section{TECNOLOGIAS DE COLETA E DE TRATAMENTO DE INFORMAÇÃO}

\section{ESPACIAL}

\subsection{Cartografia}

O objetivo da Cartografia consiste em reunir e analisar dados e medidas das diversas regiões da Terra e representar graficamente em escala reduzida os elementos de configuração que possam ser claramente visíveis. A Cartografia, no sentido lato da palavra não é apenas uma das ferramentas básicas do desenvolvimento econômico, mas é a primeira ferramenta a ser usada antes que outras ferramentas possam ser postas em trabalho (Raisz, 1969; Pontes, 2002).

Os primeiros fundamentos da ciência cartográfica foram lançados na Grécia Antiga, por volta de 160 a.C. quando Hiparco utilizou pela primeira vez métodos astronômicos para determinar posições na superfície da Terra e deu a primeira solução para desenvolvimento da superfície da Terra sobre um plano. Desde então com o passar dos séculos a cartografia vem atingindo níveis mais precisos na confecção de mapas e cartas, contando com o aprimoramento da astronomia e outros métodos matemáticos, advento da agulha magnética, criação do sistema de projeção de Mercator, e mais recentemente o emprego da Aerofotogrametria e introdução da eletrônica no instrumental necessário aos levantamentos (Pontes, 2002).

Ainda segundo Pontes (2002), existem três novas Técnicas Cartográficas

- Fotogrametria: é a técnica de elaboração de mapas a partir de fotografias aéreas, utilizando-se aparelhos e métodos estereoscópicos. O mesmo que Aerofotogrametria e Estereofotogrametria.

- Sensoriamento Remoto (Teledetecção): é a forma de obtenção de um objeto ou alvo sem que haja necessariamente contato físico (presencial) com o mesmo. 
- Geoprocessamento: pode ser definido como um conjunto de tecnologias voltadas à coleta e tratamento de informações espaciais para um objetivo específico.

\subsection{Global Positioning System - GPS}

GPS (Global Positioning System) é a abreviatura de NAVSTAR GPS (Navigation System with Time and Ranging Global Positioning System). É um sistema de radionavegação baseado em satélites desenvolvido e controlado pelo departamento de defesa dos Estados Unidos da América que permite a qualquer utilizador saber a sua localização, velocidade e tempo, 24 horas por dia, sob quaisquer condições atmosféricas e em qualquer ponto do globo terrestre (Pontes,2002). Apresenta, ainda, algumas aplicações no intuito de dar uma visão global das potencialidades do GPS:

- GPS aplicado aos Transportes: muitas empresas adaptaram sistemas conjuntos GPS/SIG para fazer gestão e monitorização de frotas;

- GPS aplicado no Desporto: indispensável nos grandes ralis como o Granada-Dakar;

- GPS Aplicado à Proteção Civil: alguns serviços de proteção civil já estão também a utilizar GPS.

- GPS Aplicado à Topografia e Geodésia: o GPS é utilizado em todas as aplicações topográficas, a sua precisão milimétrica permite utilizá-lo para determinar ângulos, distâncias, áreas, coordenar pontos, efetuar levantamentos, etc;

- GPS Aplicado a fins Militares: embora a constelação de satélites só recentemente tenha sido completada, o GPS já demonstrou ser um instrumento de grande valor as forças militares norte americanas.

\subsection{SIG - Sistema de Informações Geográfica}

SIG é um conjunto de ferramentas computacionais composto de equipamentos e programas que por meio de técnicas, integra dados, pessoas e instituições, de forma a tornar possível a coleta, o armazenamento, o processamento, a análise e a disponibilização, a partir de dados georeferenciados, de informação produzida por meio das aplicações disponíveis, visando maior facilidade, segurança e agilidade nas atividades humanas referentes ao monitoramento, planejamento e tomada de decisão relativas ao espaço geográfico (Laskowski e Ribeiro, 2005).

Segundo Camara, Souza e Freitas(1996), SIG é um sistema que processa dados gráficos e não gráficos (alfanuméricos) com ênfase a análises espaciais e modelagens de superfícies. O SIG é caracterizado por:

- Integrar numa única base de dados informações espaciais provenientes de dados cartográficos, dados de censo e cadastro urbano e rural, imagens de satélite, redes e modelos numéricos de terreno; 
- Oferece mecanismos para combinar as várias informações, através de algoritmos de manipulação e análise, para consultar, recuperar e visualizar o conteúdo da base de dados e gerar mapas;

- Suporte para análise espacial de fenômenos;

- Banco de dados geográficos, com funções de armazenamento e recuperação de informação espacial.

Ainda segundo Camara, Souza e Freitas (1996), os sistemas de informação geográfica podem ser divididos em três gerações:

- Primeira geração - CAD cartográfico: sistemas herdeiros da tradição de Cartografia, com suporte de bancos de dados limitado e com o paradigma típico de trabalho sendo o mapa (chamado de "cobertura" ou de "plano de informação"). Desenvolvidos a partir do início da década de 80 para ambientes da classe de computadores VAX e, a partir de 1985, para sistemas PC/DOS. Utilizada principalmente em projetos isolados, sem a preocupação de gerar arquivos digitais de dados. Esta geração também pode ser caracterizada como sistemas orientados a projeto ("project- oriented GIS");

- Segunda geração - Banco de dados geográfico: concebida para uso em ambientes clienteservidor, acoplado a gerenciadores de bancos de dados relacionais e com pacotes adicionais para processamento de imagens. Chegou ao mercado no início da década de 90. Com interfaces baseadas em janelas, esta geração também pode ser vista como sistemas para suporte a instituições ("enterprise-oriented GIS");

- Terceira geração - Bibliotecas geográficas digitais ou centros de dados geográficos: previstos para o final da década de 90. Caracterizada pelo gerenciamento de grandes bases de dados geográficos, com acesso através de redes locais e remotas, com interface via WWW (World Wide Web). Requer tecnologias como bancos de dados distribuídos e federativos permitindo interoperabilidade, ou seja, o acesso de informações espaciais por SIGs distintos. Sistemas orientados para troca de informações entre uma instituição e os demais componentes da sociedade ("society-oriented GIS").

\section{APLICAÇÕES DO GEOPROCESSAMENTO}

Segundo Camara, Souza e Freitas (1996), as classes de aplicações de Geoprocessamento são:

- Projetos de análise espacial sobre regiões de pequeno e médio porte. Por exemplo geração de relatórios de impacto ambiental para criação de uma hidroelétrica ou traçado de uma ferrovia. Requerem grande flexibilidade e abrangência das funções do SIG, para dados de quantidade limitada, mas muito variada.

- Inventários espaciais sobre grandes regiões. Por exemplo, levantamentos sistemáticos, como os feitos pelo INPE (Instituto Nacional de Pesquisa Espacial) para mapear o 
desflorestamento na Amazônia. Ênfase maior no tratamento de grandes bases de dados, sendo que os mesmos procedimentos são repetidos para todos os dados.

Já Laskowski e Ribeiro(2005) citam as seguintes aplicações:

- MEIO AMBIENTE - As ferramentas de geo, principalmente as de sensoriamento remoto (imagens de satélites e radares), têm sido intensivamente usadas para esta aplicação.

- PLANEJAMENTO ESTRATÉGICO DE NEGÓCIOS - Os novos conceitos de business intelligence não podem prescindir das ferramentas de geoprocessamento. Elas são capazes de mapear, literalmente, vários fatores críticos do sucesso de um negócio, respondendo a questões como: onde estão os clientes, onde estão os fornecedores, onde estão os concorrentes, entre outros Estas aplicações das geotecnologias têm sido chamadas de geomarketing ou estudos de geografia de mercado.

- AGRONEGÓCIOS - O uso de imagens de satélites e softwares específicos permite monitorar e prever safras. Da mesma forma, o domínio do componente geográfico permite o melhor planejamento e uso do solo, gestão de bacias hidrográficas e tratamento de curvas de nível para plantio e detecção de pragas. Outra aplicação é para a chamada Agricultura de Precisão, que consiste em fazer uso de equipamentos GPS e sistemas GIS permitindo o tratamento e análise de dados coletados no campo.

\subsection{Aplicação do Geoprocessamento no Urbanismo}

O universo de aplicações urbanas de SIG é bastante extenso. Existem aplicações em praticamente todas as áreas de atuação do poder público no município, bem como nas atividades relacionadas à oferta e à prestação de serviços à população (Davis Jr, 2000).

Segundo Laskowski e Ribeiro (2005), a gestão municipal é um uso clássico do geoprocessamento. Estima-se que cerca de $80 \%$ das atividades efetuadas numa prefeitura sejam dependentes do fator localização. Para as ações de planejamento urbano, os SIG são capazes de relacionar o mapa da cidade ao banco de dados com as informações de interesse do planejador.

Por exemplo, é possível relacionar onde estão os postos de saúde versus população atendida, localização das escolas versus endereços dos alunos em potencial, pavimentação versus ruas de maior movimento, ou quaisquer outros cruzamentos de dados que levem em conta a componente espacial. Áreas de saúde pública podem mapear ocorrências de endemias e agir diretamente nos locais onde ocorrem, aumentando as chances de sucesso. Para o cadastro imobiliário, é possível relacionar cadastros urbanos versus sua localização espacial versus valores cobrados versus situação do contribuinte. Os profissionais envolvidos com geoprocessamento na gestão municipal são os cartógrafos, geógrafos, arquitetos urbanistas, administradores urbanos, estatísticos, analistas de sistemas, entre outros, envolvidos com a administração pública municipal. 
Ainda segundo Laskowski e Ribeiro (2005), os serviços públicos de saneamento, energia elétrica e telecomunicações podem se valer das geotecnologias para relacionarem as suas redes de distribuição às demais informações de seus bancos de dados. Particularmente, o mercado de telecomunicações está se aproximando muito do mercado de geoprocessamento, criando um novo segmento, chamado de LBS (Location Based Services), que pode ser definido como sendo uma solução para um problema dependente de localização (ou o fator localização agregando valor a outros serviços), disponibilizado em equipamento portátil ou móvel. As soluções de LBS, porém, são projetadas para serem acessíveis através de conexões com e sem fio, web browsers e pagers.

Os profissionais envolvidos com geoprocessamento nos serviços públicos são: engenheiros (eletricistas, de telecomunicações, civis), analistas de sistemas, entre outros, envolvidos com atividades relacionadas aos serviços de utilidades.

Alguns exemplos de aplicações no urbanismo são:

- Projetos de Vias (rodovias, ferrovias, canais), de irrigação, de loteamento, drenagem, lavra.

- Operação de redes de utilidades (água, esgoto, telefone, gás), redes de transportes.

- Planejamento Urbano, regional, agrícola, e de transporte.

- Análises Espaciais Ambiental, geológicas, urbanas, regionais e de transporte.

- Gerenciamento de Processos Agrícolas e de variados processos de distribuição e de alocação.

- Monitoramento de processos ambientais, urbanos e regionais.

- Locação de vias, redes de utilidade, equipamentos, plantio.

As possibilidades de utilização do geoprocessamento pelas prefeituras abrangem várias áreas. Qualquer setor que trabalhe com informações que possam ser relacionadas a pontos específicos do território pode, em princípio, valer-se de ferramentas de geoprocessamento. Nesse mesmo espaço, porém, convivem empresas de "economia mista", privadas e concessionárias de serviços que atuam no território do município, possuindo regras e metodologia própria de ação, nem sempre integrada com a prefeitura. Certamente esse ambiente dificulta a implantação do Geoprocessamento, uma vez que as ações não estão sujeitas a um comando central e, por conseguinte, trabalham em bases diferentes (Vaz, 1997; Francisco Filho, 2005).

O geoprocessamento é um investimento com alta taxa de retorno para a prefeitura. Além dos benefícios financeiros, o geoprocessamento funciona como uma ferramenta de aumento da eficiência e da eficácia das ações da prefeitura (Vaz, 1997).

\subsubsection{Planejamento Urbano}

O planejamento é fundamental como instrumento de administração pública. No entanto, sem informações corretas, atuais e consistentes, não é possível planejar adequadamente. Isto porque o crescimento urbano é um processo espacial dinâmico, onde a 
compreensão da atualidade abrange a percepção histórica da evolução da cidade é também o potencial de mudanças para o futuro próximo.

A utilização do sistema de informações geográficas para o planejamento permite:

- a construção de um modelo, baseado em entidades espaciais, para diagnóstico do crescimento e dinâmica espacial urbana;

- o monitoramento do crescimento urbano;

- a definição das tendências de expansão;

- a identificação dos agentes que interferem neste processo de crescimento e a sua dinâmica de atuação;

- análise dos impactos causados por atividades poluidoras;

- escolha de áreas para pólos industriais;

- o cruzamento entre as informações tributárias das três esferas de governo, visando identificar focos de sonegação fiscal.

É típico do geoprocessamento a elaboração de mapas temáticos, indicativos do crescimento da cidade, e que apresentem correlações entre os diversos componentes da infra-estrutura urbana. Tais mapas revelam a dinâmica dos vetores de crescimento urbano, identificando também áreas em que ocorreram distorções no processo de desenvolvimento. Tendo sido determinados os vetores de crescimento, pode-se a seguir identificar os agentes de transformação urbana, bem como a sua dinâmica de atuação. A realização de diversas análises setoriais, que é freqüentemente feita pelos técnicos de planejamento urbano, seria bastante simplificada pela utilização do geoprocessamento. Por exemplo, analises que envolvam simultaneamente a localização de um determinado tipo de atividade econômica, e a correlacione com dados de infra-estrutura urbana e de demografia. O geoprocessamento funciona significativamente bem neste tipo de situação, tanto na fase de coleta e representação de informações, quanto na visualização de resultados, utilizando os recursos gráficos do sistema.

\subsubsection{Redes de Serviços Públicos}

De modo geral, as concessionárias de serviços públicos tais como eletricidade, saneamento e telefonia são obrigadas a lidar com uma quantidade muito grande de informações espaciais. Saber onde se encontra cada componente de uma rede elétrica, hidro-sanitária ou telefônica é critico para estas empresas. Não apenas porque se trata de boa parte do patrimônio da empresa, mas também porque o conhecimento profundo da rede, em seus mínimos detalhes, pode ser de crucial importância para a eficiência do serviço.

Assim, por exemplo, é crítico em uma interrupção no fornecimento de energia à concessionária identificar a fonte do problema, para corrigi-lo no menor prazo possível. 
No entanto, boa parte das informações necessárias para este tipo de atendimento (manutenção de redes) está contido em plantas e projetos. Dificilmente estes dados estarão informatizados, o que acarretará uma demora significativa no atendimento. Algumas empresas implementam sistemas alfanuméricos complexos, no intuito de minimizar esta lacuna. A maioria, no entanto, conta com a experiência de funcionários com muitos anos de casa, profundos conhecedores empíricos das instalações e suas peculiaridades. Estes funcionários constituem na prática a "memória humana" da concessionária, e sua disponibilidade é sempre crítica para as tarefas de manutenção.

Os SIG são sistemas capazes de realizar esta tarefa com mais eficiência, pois permitem não apenas uma melhor visualização do problema, no instante em que ocorre, mas também pode oferecer ferramentas de analise que facilitarão a diagnose do problema e acelerarão sua solução.

Além de ajudar na solução dos problemas de manutenção, os SIG poderão atuar nas seguintes áreas:

- catalogação patrimonial

- projeto de novas redes

- realização de estudos de impacto ambiental

- dimensionamento de demanda.

- simulação de manobras/operações]

\subsubsection{Transportes}

A área de transportes é também tradicional na aplicação de SIG, que pode ser dividida em duas áreas:

- Aplicações voltadas para o planejamento e simulação do funcionamento do sistema viário e meio de transporte, públicos e privados;

- Aplicações voltadas para a prestação de serviços apoiados na rede viária, tais como planejamento de coletas de entregas e distribuição de produtos.

Ambas as áreas demandam um grande volume de informações sobre a malha viária, compreendendo principalmente o traçado das vias (por meio de eixos de vias ou centerlines), sentido de tráfego e conversões permitidas, tipo de pavimentação, e os nomes das vias (oficiais e populares). Para o poder público, serão ainda necessárias informações sobre a sinalização viária, para fins de manutenção.

O tipo de análises é um processamento tipicamente realizado pelas aplicações de transportes e o de caminho mais curto ou de caminho ótimo. São as aplicações que desejam determinar, por exemplo, qual a melhor rota para o tráfego de um caminhão transportando carga perigosa, ou qual a melhor opção para a percorrer a distância entre dois pontos utilizando o sistema público de transporte coletivo. No entanto, a área de transportes demanda uma grande variedade de aplicações, entre elas:

- planejamento de capacidade e manutenção de vias 
- manutenção da sinalização

- clustering: agrupamento de pontos de entrega ou coleta, para maximizar a eficiência de uma frota de veículos

- registro e acompanhamento estatístico de acidentes de tráfego

- roteamento de cargas intermunicipais e interestaduais

- vehicle tracking ou automatic vehicle location: acompanhamento dinâmico do posicionamento de veículos através do sistema GPS

Esta última aplicação tem dois extremos: a localização de viaturas policiais no ambiente urbano, e o acompanhamento por satélite de caminhões em estradas. Em ambos os casos, utilizam-se geoprocessamento acoplado a receptores GPS, colocados nos veículos, e capazes de transmitir as coordenadas atuais para uma estação central.

\subsubsection{Segurança Pública}

Diversos tipos de aplicações geográficas são possíveis na área de segurança pública. Para começar, a localização geográfica de recursos e unidades e um fator fundamental para a logística envolvida nas operações de segurança, possibilitando:

- criar áreas de jurisdição associadas a instalações fixas

- planejar o patrulhamento regular

- conceber, planejar e executar operações especiais

- analisar possíveis rotas de fuga de criminosos

- analisar estatisticamente o perfil da violência urbana através da localização geográfica de ocorrências policiais

- agilizar o atendimento a chamadas de emergência.

O mapeamento criminal constitui uma das diversas aplicações do Geoprocessamento em Gestão Pública, apresentando-se como uma poderosa ferramenta a serviço da justiça e do combate à criminalidade (Rosette, Menezes, Silva, 2004).

Boa parte dessas aplicações tem relação direta com a malha de circulação viária, pois o deslocamento de viaturas ocorre em função das regras de trânsito estabelecidas. Também é muito importante o relacionamento com informações sócio-econômicas, que permitem desenvolver uma melhor visão da ligação que existe entre determinados tipos de ocorrências e a qualidade de vida da população em cada região.

\section{EXEMPLO DE UM SISTEMA DE GEOPROCESSAMENTO}

A cobrança do IPTU (Imposto Predial Territorial Urbano) em prefeituras municipais de pequeno e médio porte é à base da arrecadação municipal. Entretanto, na maioria destas 
prefeituras, a cobrança dos impostos é baseada em um banco de dados alfanumérico, sem qualquer referência espacial. O registro de novas construções, reformas ou lotes desmembrados só são feitos se o proprietário atualizar seus dados junto à prefeitura municipal. O desvio destas informações leva a uma sub-tributação, onde perde o município como um todo.

Baseado no artigo de Skroch, Silva, Marchis, Lopes e Fonseca (2003), será tratado um exemplo de SIG, para solucionar o problema do gerenciamento das informações relativas ao IPTU.

As aplicações de um sistema de informações deverão estar compatíveis com os objetivos de uma prefeitura, como aperfeiçoar e agilizar o atendimento ao contribuinte, como controlar e gerenciar a quantidade e qualidade dos serviços públicos e comunitários, como praticar uma política tributária justa e igualitária, como desenvolver e implantar ações de planejamento urbano a partir do real conhecimento da estrutura físico-territorial de seu município, entre outras.

\subsection{Softwares Utilizados}

Existem diversos softwares de geoprocessamento no mercado, como por exemplo o Spring e o MaxCAD, cada qual com um conjunto particular de recursos e com os mais variados preços. Antes de optar por qual software se deve comprar é preciso levar em consideração a expectativa e as necessidades da organização interessada. Alguns sistemas simples, que se baseiam na consulta a banco de dados com visualização na base cartográfica digital não podem ser considerados Sistemas de Informação Geográfica, pois se privam dos recursos de análise baseada na topologia dos elementos.

Entretanto, tais sistemas podem atender às expectativas de prefeituras de pequeno e médio porte, oferecendo uma solução viável quando se dispõe de limitados recursos financeiros. Estes sistemas apresentam vantagens em relação a um SIG pelo fato de serem mais simples, facilitando a etapa de aprendizado e treinamento.

\subsubsection{Sistema Gerenciador de Banco de Dados}

Um sistema de gerenciador de banco de dados (SGBD) consiste numa coleção de dados inter-relacionados e um conjunto de programas para acessar esses dados. A coleção de dados é comumente referenciada como o banco de dados, que contém informação de um particular empreendimento. O principal objetivo de um SGBD é proporcionar um ambiente, conveniente e eficiente, para retirar e armazenar informação no banco de dados.

\subsection{Execução}


Normalmente as cidades são divididas em setores para facilitar o trato das informações Em cada setor existem informações sobre edificações residenciais, comerciais e públicas, lotes vagos, mais de uma edificação em um lote, etc.As etapas para inicializar o trabalho são visualizadas no diagrama a seguir:

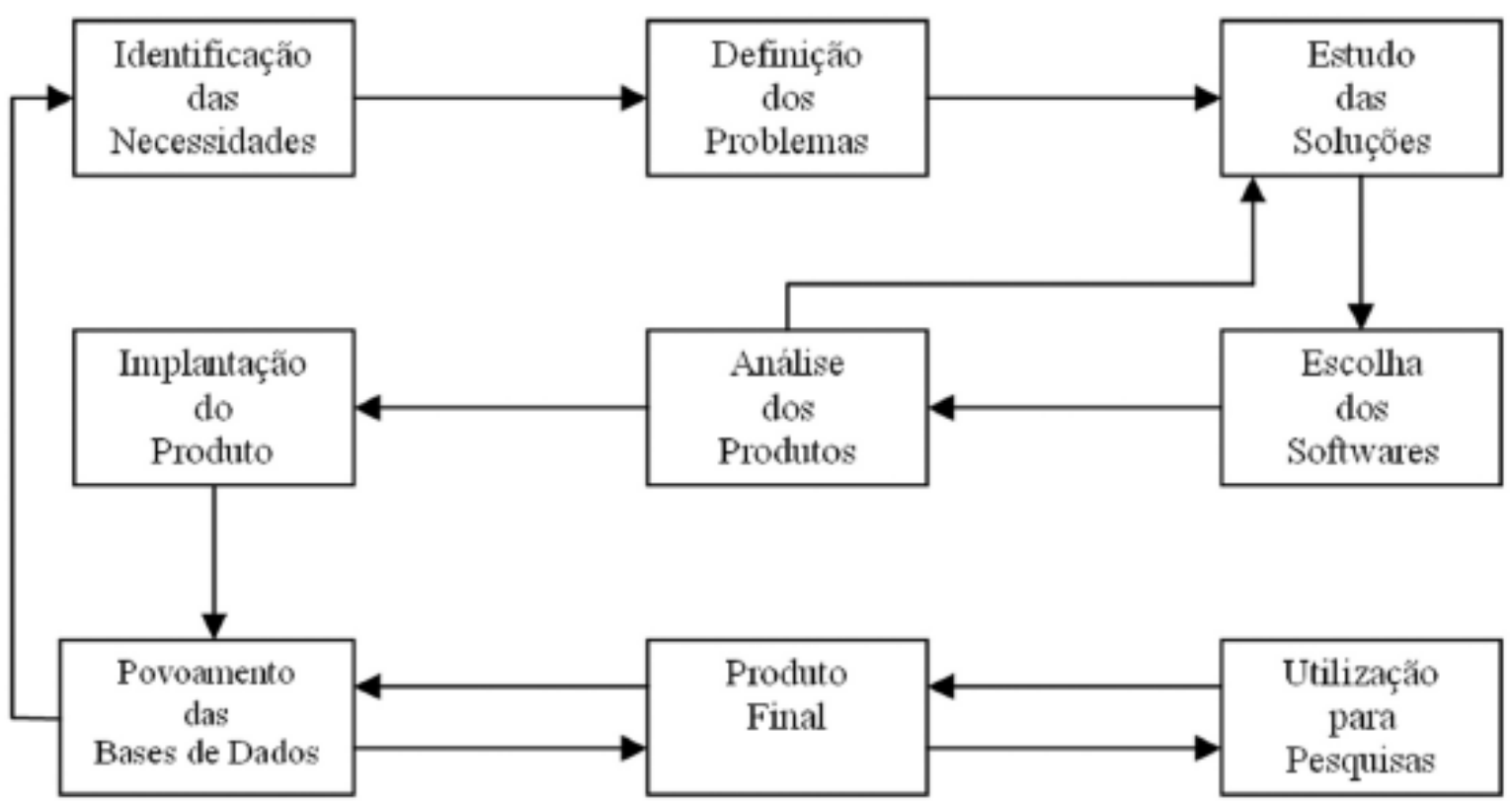

Figura 1 - Ciclo de Geoprocessamento Urbano

\subsubsection{Verificação do Cadastro Imobiliário}

Para início dos trabalhos, é realizada uma verificação e atualização das fichas cadastrais da prefeitura. São verificadas, utilizando trena, as medidas de fachadas dos lotes, bem como os dados referentes aos proprietários. Tais dados referem-se a: informações principais do lote como inscrição cadastral, nome do proprietário, logradouro do proprietário, dados sobre o terreno, logradouro do lote, informações gerais sobre o imóvel e o total de prova, que consiste no somatório dos campos preenchidos nas fichas.

- $\quad$ detalhes da residência (quando houver), como:

1) tipo, alinhamento, localização, posição, estrutura, cobertura, vedação e forro;

2) tipo de revestimento externo, número de sanitários, instalação elétrica, piso, lançamento e conservação;

3) informações relacionadas a dimensionamento das testadas e áreas relacionadas aos lotes e edificações.

- Fazer as correções e atualizações necessárias às fichas cadastrais já existentes na prefeitura.

\subsubsection{Adequação da Base Cartográfica}


Com as informações coletadas em campo, serão definidos os níveis de informação de interesse: quadras, lotes, edificações, edificações atualizadas e toponímias. A partir destes níveis serão realizadas algumas correções para adequar a base para a etapa de processamento de informações. Após a edição das entidades para o fechamento, serão inseridas as chaves de acesso de cada quadra, lote e edificação, onde, a ligação do banco de dados com o mapa digital se dá através destas chaves de acesso, que devem ser comuns aos dois sistemas. As chaves de acesso foram definidas a partir da inscrição cadastral do lote, que podem ser, por exemplo, identificados da seguinte maneira:

\begin{tabular}{|l|l|l|l|l|}
\hline Aa & bb & ccc & Dddd & eee \\
\hline municipio & setor & quadra & Lote & edificação \\
\hline
\end{tabular}

Por exemplo, na inscrição cadastral 11-01-003-0010-001, a chave de acesso da quadra é 1101003, do lote 11010030010 e da edificação 11010030010001.

\section{DISCUSSÃO DOS SISTEMAS -}

\section{VANTAGENS E DESVANTAGENS}

Discutindo o exemplo de sistema de geoprocessamento citado no capítulo anterior, serão mostradas as vantagens e desvantagens em implementá-lo em uma prefeitura de pequeno e médio porte. O sistema busca sanar as necessidades previstas pela instituição, tendo isso como uma vantagem, porem existem problemas já previstos na implementação deste sistema, sendo isto uma desvantagem, que podem ser amenizados.

\subsection{Necessidades Previstas}

- Confiabilidade: a confiabilidade dos dados cadastrais é um fator importante para o aumento da arrecadação do IPTU. A atualização das informações espacialmente referenciadas traz benefícios aos diversos setores da administração, permitindo, por exemplo, planejar obras de melhoria e expansão dos serviços comunitários, fazer análises espaciais sobre variáveis como educação e saúde, ou verificar espacialmente a cobrança dos impostos.

- Integração dos dados: a melhoria da utilização das informações relativas ao cadastro imobiliário seria útil para todos os seus departamentos, pois permitiria a unificação de informações para toda a prefeitura, possibilitando a implantação de um sistema onde a administração municipal tenha um total controle da cobrança dos impostos e do planejamento urbano.

\subsection{Problemas Previstos}

- Gerenciar informações aliando-as à referência espacial: a falta de referência espacial não permite que sejam realizados os planejamentos adequados em diversos setores. 
- Alto custo e demora em atingir os objetivos esperados pelas administrações: Existe um alto custo em termos de hardware, software, treinamento de pessoal e suporte técnico. Os benefícios seriam sentidos apenas a médio e longo prazo quando o esperado seria uma solução mais simples, que permita a obtenção de resultados rápidos, concretos e com boa qualidade.

A implantação de um SIG deve ser encarada como uma tarefa de médio prazo, na busca da eficiência das atividades técnicas e administrativas. Mas, não se pode crer que a simples aquisição de hardware e de software configurem uma solução para tanto, pois a sua implantação implica na informatização das rotinas da administração municipal.

Já em prefeituras pequenas e médias, esses problemas são minimizados, pois existem maiores chances de utilização racional do espaço urbano. Devido ao baixo grau de urbanização, as demandas em termos de planejamento e administração são mais simples, necessitando de equipamentos e processos menos complexos para resolvê-los. Os dados relativos a estas áreas urbanas podem ser armazenados e gerenciados em bancos de dados para PC’s. Conseqüentemente, os recursos financeiros são significativamente menores e as metodologias podem ser assimiladas facilmente por técnicos de menor nível de especialização.

\section{Conclusão}

O fator localização é muito importante para o controle das mais variadas tarefas do ser humano. Sendo assim, o geoprocessamento nos auxilia em diversas áreas do conhecimento, facilitando um melhor relacionamento entre o homem e o espaço onde ele vive.

Com a adoção do caso exemplo discutido, foi possível visualizar a formalização das diretivas básicas necessárias à integração do sistema de geoprocessamento proposto. Esta formalização poderá diferenciar em termos básicos de caso a caso, porém irá conter as diretivas necessárias aos sistemas de controle de características urbanas.

Com a análise dos itens descritos neste trabalho concluiu-se que o geoprocessamento é uma ferramenta importante para uma gestão pública tornando-se indispensável para uma administração eficiente, auxiliando nas tomadas de decisões e no planejamento de um crescimento estruturado das áreas urbanas. Embora os recursos do geoprocessamento ainda sejam de difícil acesso para prefeituras de pequeno porte, hoje já existem soluções mais 
acessíveis e de resultados eficientes tais como as discutidas no exemplo apresentado no presente trabalho.

\section{Referências Bibliográficas}

Laskowski S.B. , Ribeiro E. SIG - Sistema de Informação Geográfica

Disponível em www.fatorgis.com.br Acessado em maio de 2005.

Camar G, Souza R.C.M., Freitas U.M., Garrido J. SPRING - Integrating remote sensing and GIS by object-oriented data modeling, 1996

Disponível em http://citeseer.ist.psu.edu/camara96spring.html , acessado em maio 2005

Pontes M.A.G. GPS - Sistema de Posicionamento Global, 2002.

Disponívelhttp://www.facens.br/site/alunos/download/topografia/apostila_Geoprocessamen

to_2.pdf acessado em abril 2005

Cartografia, 2002.

Disponível http://www.dpi.ufv.br/ jugurta/papers/exqual.pdf acessado em abril 2005

GIS e Geoprocessamento, 2002.

Disponívelhttp://www.facens.br/site/alunos/download/topografia/apostila_Geoprocessamen to_2.pdf acessado em abril 2005

Neto S.L.R. Geoprocessamento

Disponível em: www.cav.udesc.br/ engrural/ie/eventos/ursosig.html Acessado maio de 2005.

Laboratório de geoprocessamento da Escola politécnica da USP - Informações

Disponível em: < http://www.ptr.poli.usp.br/labgeo/ginfo.html> Acessado maio de 2005.

Vaz J.C. , Petrucci V., Rolnik R - Geoprocessamento Urbano

Disponível em: www.federativo.bndes.gov.br/dicas/D094\%20\%20Geoprocessamento.htm Acessado em 28 de abril de 2005.

Francisco Filho, L. L. - O Uso do Geoprocessamento como apoio na Gestão do município Disponível em: www.fec.unicamp.br/ llfilho/ Acessado abril de 2005. 
Gewin, V. - Mapping Opportunities - Revista Nature volume 427 , 22 de janeiro de 2004.

Davis JR, Clodoveu - Cartografia Automatizada e SIG, Texto extraido dos anais do congresso GIS BRASIL 97, CD ROM, Sagres Editro, Curitiba, 1997.

Skroch L.S.D, Silva A. C., Marchis C.K., Lopes E.A, Fonseca R.N.- Desenvolvimento de um Sistema para Gerenciamento Espacial do Iptu em Municípios de Pequeno e Médio Porte, 2003.

\section{Informações bibliográficas:}

Conforme a NBR 6023:2002 da Associação Brasileira de Normas Técnicas (ABNT), este texto científico publicado em periódico eletrônico deve ser citado da seguinte forma:

ALMEIDA, F. L.; COSTA, G. M.; NASCIMENTO, Ricardo Passos; LEITE, V. M.; LOBÃO, Diomar Cesar; GENESTRA, M. S.; OSÓRIO, T. L. G.; CARELLI, F. C.. Geoprocessamento no Trato de Controle de Características Urbanas. Cadernos UniFOA , Volta Redonda, ano 2, n. 3, mar. 2007. Disponível em:

$<$ http://www.unifoa.edu.br/pesquisa/caderno/edicao/03/21.pdf> 